\title{
What Will Make Hospital Pharmacists Successful as They Take On an Expanded Scope of Practice?
}

\author{
Marc Perreault
}

$\mathrm{O}$ ver the past 5 years, most Canadian provinces have enacted legislative changes allowing an expanded scope of practice for pharmacists. These changes, which are consistent with the objectives of the CSHP 2015 initiative, ${ }^{1}$ are intended to assist patients to achieve the best outcomes from their medications, as well as to improve medication safety. For hospital pharmacists, the expanded scope of practice includes activities such as changing drug dosages and other aspects of patients' prescriptions, therapeutic substitution, initiation of prescription drug therapy (including therapy for minor ailments), and ordering and interpretation of laboratory tests, all of which have further focused the pharmacist's role within a patient-centred model of care. These changes should be welcomed by the vast majority of hospital pharmacists; however, implementation has been slow. Consequently, it is timely and relevant to ask "What will make us successful in embracing an expanded scope of practice?"

In this issue, Hwang and others ${ }^{2}$ present a study in which they assessed the impact of an expanded scope of practice that had been introduced at a community hospital. Dose titration and reordering of medications for chronic conditions were the most frequently performed activities. Pharmacists and physicians participating in patient care agreed that the expanded scope of practice for pharmacists improved the overall quality of comprehensive patient care and enhanced the autonomy and recognition of pharmacists. Not surprisingly, lack of time was identified by the pharmacists as the most common barrier to offering a more patient-centred practice. Such a barrier can be expected whenever additional tasks or a newly defined role is brought forward. However, it should not deter pharmacists from embracing an expanded scope of practice.

Knowledge about drugs and diseases and the ability to apply this knowledge are key components of success. Undergraduate pharmacy programs and residency programs are geared to ensure that pharmacy graduates have what it takes to meet the needs of current and future patients. Across Canada, faculties of pharmacy are shifting from the traditional undergraduate pharmacy degree to entry-level PharmD programs, which provide much greater experiential training consistent with an expanded scope of practice. In addition, highquality continuing education programs are mandatory to expand the knowledge and skills of practising pharmacists and must be developed and delivered in a timely manner.

Another important key to success is commitment to patient care. As pointed out by William Miller, recipient of the 2005 Paul F Parker Award from the American College of Clinical Pharmacy, individuals who create change are committed and passionate about their work, their profession, their families, and their friends. ${ }^{3}$ In a patient-centred model, pharmacists who are committed to their patients will have a positive impact on outcomes and will likely experience significant gratification from their work.

Finally, we cannot address the elements of success in embarking on an expanded scope of practice without focusing directly on hospital pharmacists themselves. The intrinsic nature of these practitioners definitely affects their ability to take on this role. Also in this issue, Hall and others ${ }^{4}$ explore the personality traits of hospital pharmacists that influence pharmacy practice change. The authors surveyed hospital pharmacists in Alberta and used a validated instrument to evaluate a defined set of 5 personality traits. The majority of the 347 hospital pharmacists who responded to the survey displayed strong expressions of extraversion, agreeableness, conscientiousness, and openness, as well as emotional stability. The single most influential factor enabling pharmacists to adopt an expanded scope of practice is currently unknown, and isolating such a characteristic promises 
to be very difficult. However, subgroup analyses revealed that those with additional prescribing authority tended to be more extraverted (with characteristics of sociability, assertiveness, confidence, and ambitiousness). Intuitively, I believe that openness (i.e., originality, ingenuity, curiosity, and artistic orientation) and conscientiousness (i.e., reliability, thoroughness, tenacity, efficiency, and organized behaviour) will also play significant roles in successful adoption of this new role. Conversely, overconscientiousness may be a deterrent to exploring new roles.

So what makes hospital pharmacists successful? Our knowledge and skill sets gained through education and experience, our collaboration with physicians, our commitment to patient care, and our extraverted nature are all determinants of success, even though lack of time can be a significant barrier. Research exploring the traits of hospital pharmacists as they relate to an expanded scope of practice is in its infancy but holds promise of enabling development of programs that will support these health care professionals to adopt and adapt such practice. Furthermore, this research will help in developing tools to refine the process of selecting pharmacy students who naturally display the traits compatible with an expanded scope of practice in a patientcentred model.

\section{References}

1. CSHP 2015 status: goals and objectives. Ottawa (ON): Canadian Society of Hospital Pharmacists; 2011 [cited 2013 Jul 20]. Available from: www.cshp.ca/programs/cshp2015/docs/CSHP2015GoalsandObjectives StatusReportMay2011.pdf

2. Hwang S, Koleba T, Mabasa VH. Assessing the impact of an expanded scope of practice for pharmacists at a community hospital. Can J Hosp Pharm. 2013;66(5):304-9.

3. Miller WA. Creating change in your profession. Pharmacotherapy. 2007; 27(2):171-4.

4. Hall J, Rosenthal M, Family H, Sutton J, Hall K, Tsuyuki RT. Personality traits of hospital pharmacists: toward a better understanding of factors influencing pharmacy practice change. Can J Hosp Pharm. 2013;66(5):289-95.

Marc Perreault, MSc, PharmD, BCPS, is a Critical Care Pharmacist at the Montreal General Hospital, Montréal, Quebec. He is also an Associate Editor with the CJHP.

Competing interests: None declared.

Address correspondence to:

Dr Marc Perreault

Pharmacy Department

Montreal General Hospital

1650 Cedar Avenue, Suite C1-200

Montréal QC H3G 1A4

e-mail: marc.perreault@umontreal.ca

\section{ON THE FRONT COVER}

\section{Thanksgiving North of Medicine Hat, Alberta}

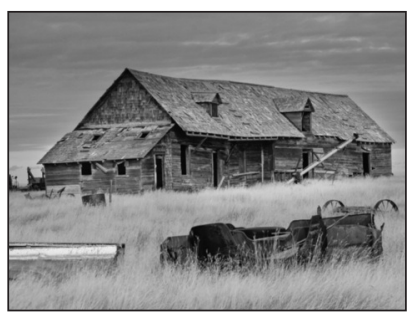

CSHP member Ken Wou (Pharmacy Manager, SouthEast, Alberta Health Services) describes this issue's cover photograph in his own words: "It was mid-October, Thanksgiving weekend, and I was going to fetch me a turkey. We drove about an hour north of Medicine Hat, Alberta, when we stumbled across this abandoned barn, evoking memories from yesteryear. I pulled out my Canon 50D, loaded it up with a 24-105 mm lens, and fired away. I used a tripod to keep most things steady, though it was really windy, which lent the grass a pastel-like texture. The sky was slightly overcast, so there were no harsh shadows. The resulting shot was better than any turkey!"

The CJHP would be pleased to consider photographs featuring Canadian scenery taken by CSHP members for use on the front cover of the journal. If you would like to submit a photograph, please send an electronic copy (minimum resolution $300 \mathrm{dpi}$ ) to Colleen Drake at cdrake@cshp.ca. 